\title{
Diaporthe phaseolorum var. caulivora, a Causal Agent for Both Stem Canker and Seed Decay on Soybean
}

\author{
Suli Sun ${ }^{1}$, Kyujung Van ${ }^{1}$, Moon Young Kim ${ }^{1}$, Kyung Hun Min ${ }^{2}$, Yin-Won Lee ${ }^{2}$ and Suk-Ha Lee ${ }^{1,3 *}$ \\ ${ }^{1}$ Department of Plant Science and Research Institute for Agriculture and Life Sciences, Seoul National University, Seoul 151-921, Korea \\ ${ }^{2}$ Department of Agricultural Biotechnology and Center for Fungal Pathogenesis, Seoul National University, Seoul 151-921, Korea \\ ${ }^{3}$ Plant Genomics and Breeding Institute, Seoul National University, Seoul 151-921, Korea
}

(Received on October 17, 2011; Revised on November 29, 2011; Accepted on November 30, 2011)

\begin{abstract}
Northern stem canker caused by Diaporthe phaseolorum var. caulivora $(D p c)$ has become a serious disease in soybean. The objectives of this study were to survey the existence of $D p c$ on soybean in Korea, and to examine the potential pathogenicity of $D p c$ in seed decay. One such isolate, SSLP-4, isolated from a field-grown plant of the Korean soybean cultivar Danbaekkong, was identified as $D p c$, based on its morphological and molecular characteristics by sequences of internal transcribed spacer (ITS), translation elongation factor (TEF) 1- $\alpha$ and $\beta$-tubulin regions, as well as pathogenic analyses. Moreover, morphological and molecular analyses revealed that isolate SSLP-4 was nearly identical to Dpc strains from the United States. Pathogenicity tests on hypocotyls of soybean seedlings and detached leaves resulted in typical symptoms of soybean northern stem canker and inoculation on plants at R5-R7 stage caused seed decay. All results suggest that the Dpc strain SSLP4 can cause both stem canker and seed decay on soybean. Thus, the SSLP-4 isolate has the potential to contribute greatly to understanding of host plant resistance mechanisms, both at vegetative and reproductive growth stages in soybean.
\end{abstract}

Keywords : Diaporthe phaseolorum var. caulivora, Diaporthe/ Phomopsis complex, Phomopsis seed decay, soybean northern stem canker

Soybean stem canker caused by Diaporthe phaseolorum var. caulivora $(D p c)$ was first found in Iowa in the 1940s (Welch and Gilman, 1948). Welch and Gilman (1948) initially identified this pathogen as $D$. phaseolorum (Cooke \& Ellis) Sacc. var. batatatis (Harte \& Field) Wehm. Until 1954, this pathogen was considered a new pathogen and was named $D$. phaseolorum (Cooke \& Ellis) Sacc. var. caulivora (Athow \& Caldwell), following with adding the

\footnotetext{
*Corresponding author.

Phone) +82-2-880-4545, FAX) +82-2-877-4550

E-mail)sukhalee@snu.ac.kr
}

disease name forwarded with soybean stem canker (Athow and Caldwell, 1954). In the 1950s, stem canker became a destructive disease on soybean (Glycine max (L.) Merril) in the north-central regions of United States and Canada (Crall, 1956; Hildebrand, 1956). This epidemic was finally brought under control by planting new resistant varieties (Athow and Caldwell, 1954). However, in 1973, soybean stem canker reappeared in Mississippi, USA. A few years later, its occurrence was reported throughout the soybeanproducing areas of the southern United States (Backman et al., 1985). Based on different cultural characteristics and symptom expression of two isolates from Iowa (northern) and Mississippi (southern), soybean stem canker was divided into two types: $D p c$ causing northern stem canker and D. phaseolorum var. meridionalis (Dpm) causing southern stem canker (Smith and Backman, 1988). Dpc and Dpm belong to Diaporthe/Phomopsis complex which is a major contributor to poor seed quality and causes greater losses than any other single fungal pathogen in soybean (Hartman et al., 1999).

$D p c$ has been reported in many soybean-producing countries with high adaptability in a large number of hosts. In recent years, $D p c$ was also observed on soybean in Argentina and Brazil (Costamilan et al., 2008; Pioli et al., 2003). However, a limited number of studies have been reported on $D p c$ of soybean in Korea. The objectives of this study were to identify Korean $D p c$ strain and examine the potential pathogenicity of Korean $D p c$ strain in both stem canker and seed decay.

Symptoms of soybean northern stem canker were surveyed in 2008 from three different locations where soybean was cropped in successive years: Suwon, Daegu, and Milyang in Korea. However, plants with early symptoms of soybean stem canker, reddish-brown and slightly sunken stems, were observed only in Suwon on the soybean cultivar Danbaekkong at the Seoul National University Experimental Farm (Fig. 1A). Collected stem tissue were surfacesterilized and plated on potato dextrose agar (PDA, Difco Laboratories, Seoul, Korea) acidified with lactic acid ( $\mathrm{pH}$ 
4.5) and supplemented with $500 \mathrm{mg} / \mathrm{L}$ streptomycin (SigmaAldrich, St. Louis, MO, USA). Plates were incubated at $25^{\circ} \mathrm{C}$ with a $12 \mathrm{~h}$ light/dark regime. Single spore isolations were made for identification. Surface-sterilized stems were also placed in a moist petri dish and kept in the same condition. For morphological identification, fungal stroma in the incubated stems and colonies of isolate SSLP-4 were observed periodically for morphology under a microscope. For molecular identification, DNA was extracted and amplified with four primer sets, Phom.I/Phom.II, ITS4/ ITS5, EF1-728F/EF1-986R and Bt2a/Bt2b, distributed in ITS regions, TEF1- $\alpha$ gene, and the $\beta$-tubulin gene, respectively (Ash et al., 2010; Santos et al., 2010; Zhang et al., 1997). PCR reactions were conducted as follows: $5 \mathrm{~min}$ at $95{ }^{\circ} \mathrm{C}$ followed by 35 cycles of $45 \mathrm{~s}$ at $94{ }^{\circ} \mathrm{C}, 45 \mathrm{~s}$ at $55^{\circ} \mathrm{C}-65^{\circ} \mathrm{C}$ (depending on the primer-specific annealing temperature), and $1 \mathrm{~min}$ at $72^{\circ} \mathrm{C}$, with a final extension period of $10 \mathrm{~min}$ at $72{ }^{\circ} \mathrm{C}$. The purified products were sequenced with a forward or reverse primer and the BigDye Terminator v. 3.1 mix (Applied Biosystems, Foster City, CA, USA) on an ABI 3730xl DNA Sequencer (Applied Biosystems). Sequences were analyzed by SeqScape software v. 2.0 (Applied Biosystems). For phylogenetic tree analyses, sequences of three amplicons from the ITS, TEF1- $\alpha$ and $\beta$-tubulin regions were blasted against the GenBank database. Highly homologous sequences of ITS regions were downloaded and aligned. The tree was constructed with MEGA version 4.0 using aligned sequences (Tamura et al., 2007). The phylogenetic tree was rooted at Stenocarpella maydis used as an out-group.

Pathogenicity tests were performed during both vegetative and reproductive growth stages of soybean. Seeds of Danbaekkong were planted in $15-\mathrm{cm}$ diameter pots in a (3:2:1) fertilizer:sand:soil mix. A completely randomized design experiment with five replicates was applied. In the first assay, hypocotyls of seedlings were inoculated with mycelial plugs of isolate SSLP-4 in a humidity chamber using the modified toothpick method described by Keeling (1982). The second assay was performed on detachedleaves from adult plants, fully expanded 3- to 4-week-old trifoliate leaves, inoculated with mycelium plugs in a moist petri dish. The results of the lesions were measured 4 or 7 and 10 days post inoculation. In order to verify Koch's rules, pathogens were isolated again from around the infection points. All experiments were repeated twice.

For evaluation of potential pathogenicity of the SSLP-4 isolate in seed decay, plants of Danbaekkong during R5-R7 stage were sprayed three times with ascospore suspension of SSLP-4 at approximately $1.0 \times 10^{6}$ spores $/ \mathrm{ml}$ at $28^{\circ} \mathrm{C}$ in the greenhouse. High humidity was maintained to provide favorable conditions for infection by providing regular sprinkler irrigation. A negative control was treated in the

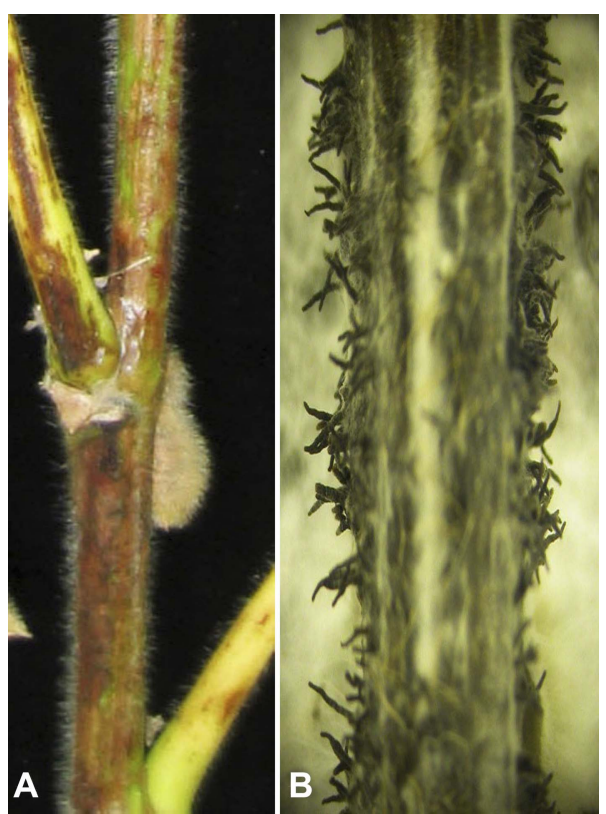

Fig. 1. Symptoms of northern stem canker. (A) Early symptoms of stem canker with reddish-brown, slightly sunken lesions on a naturally-infected soybean stem; (B) perithecia (fruiting bodies) with protruding beaks on a naturally-infected soybean stem after incubation in a moist chamber (Petri dish).

same way with sterile distilled water. In order to compare pathogenetic levels of seed decay with the primary pathogen of Phomopsis seed decay, Phomopsis longiciolla was treated in the same way as for $D p c$ inoculations. After seeds were harvested from inoculated plants, a seed bioassay was performed based on the recovery of $D p c$ as well as $P$. longicolla from seeds on acidified potato-dextrose agar (APDA). After 4 and 7 days, percentage infection was determined by counting colonies of $D p c$ and P. longicolla growing on seeds.

The isolate SSLP-4 was obtained from stems showing early symptoms of northern stem canker (Fig. 1A). In particular, the stem produced a mass of perithecia with long protruding beaks after incubation in a moist petri dish (Fig. 1B). The SSLP-4 isolate produced white colonies with dense and tufted white mycelium which occasionally turned light tan with age (Fig. 2A, C-D). The cultures occasionally produced yellow-brown pigments at the bottom. In early stages, black stromata with pycnidia were produced (Fig. 2A). The $\alpha$-conidia from pycnidia are hyaline, nonseptate, and ellipsoidal to fusiform and guttulate, ranging in size from 6.02-7.68 × 2.22-3.57 $\mu \mathrm{m}$ (Fig. 2B). Pycnidia and $\alpha$-conidia disappeared as cultures aged (Fig. 2C). After 35 days, long beaks protruded from immersed, black, globose perithecia (Fig. 2E), which were highly variable in length (230-3560 $\mu \mathrm{m})$ with some branching (Fig. 2F). The unitunicate-walled and eight-spored asci were elongate- 

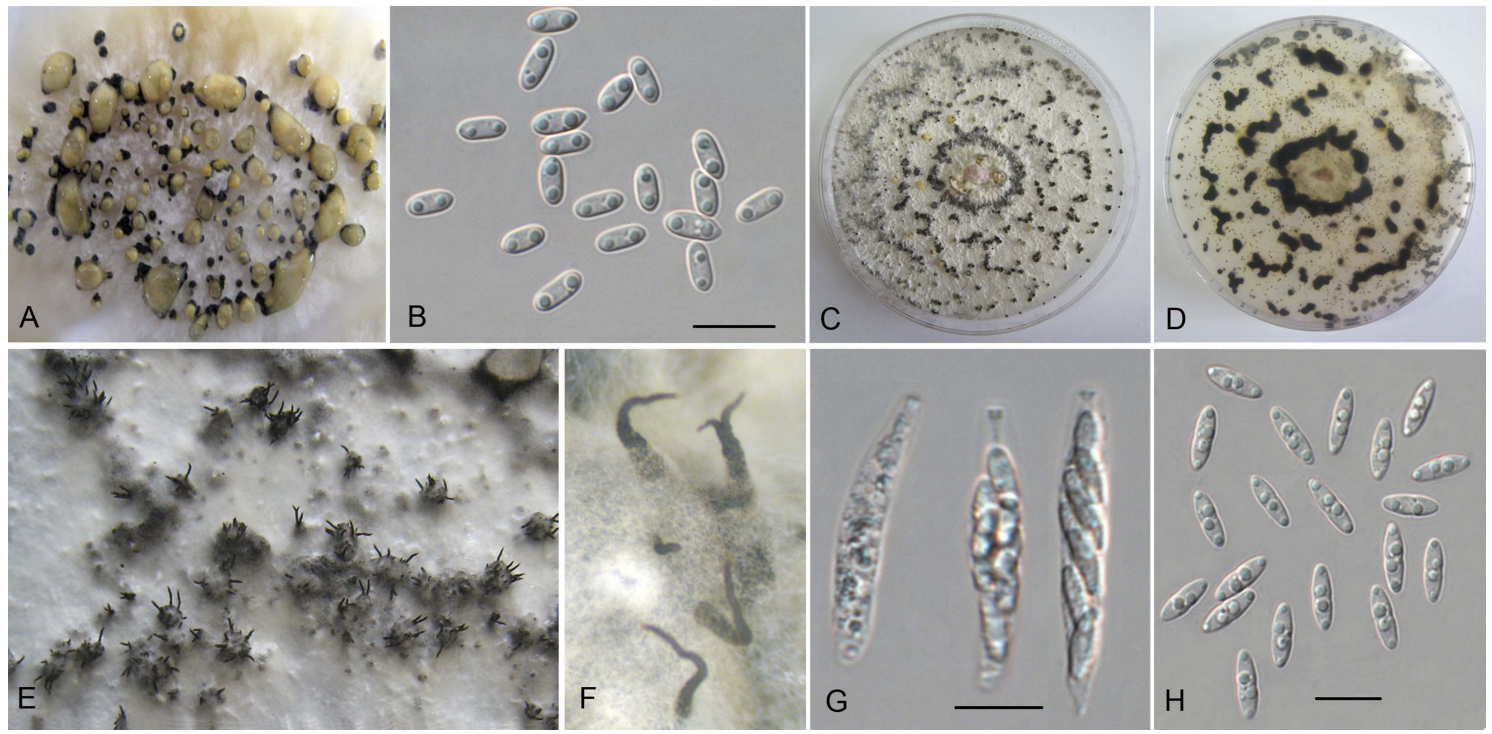

Fig. 2. Morphology of $D$. phaseolorum var. caulivora. (A) Pycnidia with extruding conidia; (B) guttulate $\alpha$-conidia; (C) upper colony surface; (D) lower colony surface; (E) embedded perithecia with protruding visible beaks; (F) long beaks with and without branch; (G) young and mature asci with apical refractive ring; $(\mathrm{H})$ ascospores with biguttulate in each cell (Scales: $10 \mu \mathrm{m})$.

clavate and sessile with a refractive ring in the apex size (Fig. 2G) of 29.92-40.27 × 6.79-11.24 $\mu \mathrm{m}$. Ascospores were hyaline, two-celled, elongate-ellipsoid, slightly constricted at the septum, and biguttulate in each cell, measuring 8.81-10.56 $\times 3.23-3.90 \mu \mathrm{m}$ (Fig. $2 \mathrm{H}$ ). The SSLP-4 isolate had an identical morphology to the $D p c$ isolate obtained from stems collected in Beltsville, MD, USA, except for a more variable length and width (Nevena et al., 1997).

For molecular identification of $D p c$, the specific primers (Phom.I/Phom.II) produced a PCR product of about $337 \mathrm{bp}$ in size, identical with that of a previous report on Diaporthe/ Phomopsis species (Zhang et al., 1997). Therefore, the isolate SSLP-4 is one of the species in the Diaporthel Phomopsis complex. After sequencing three conserved gene fragments, the sequences were submitted to the NCBI database as HQ333503 (ITS), HQ333508 (TEF1- $\alpha$ ) and HQ333513 ( $\beta$-tubulin), and were subsequently used for a BLAST search against the NCBI GenBank database. The results indicated that the sequence HQ333508 (TEF1- $\alpha$ ) is the second sequence of $D p c$ submitted to the NCBI and that it has high homology (E-value, $1 \mathrm{E}^{-123}$ ) with the first reported sequence (accession No. AF398889). Moreover, no sequences with high homology were observed for the HQ333513 ( $\beta$-tubulin) sequence of $D p c$, indicating that this sequence was unique. Hopefully, the $D p c$ sequences described in this study will provide an important reference for the comparison of $\beta$-tubulin and TEF1- $\alpha$ genes in Dpc. The ITS region HQ333503 sequence was found to be highly similar to sequences from two D. phaseolorum and many $D p c$ strains. The best matches were $D$. phaseolorum strains sw-93-11 (AF001027) and sw-93-10 (AF001026) from soybean in the USA, which had only a difference of a single base pair deletion. The phylogenetic tree was constructed using sequences of ITS regions from four species of the Diaporthe/Phomopsis complex. In the phylogenetic tree (Fig. 3), the sequence of the isolate SSLP-4 was grouped with those of four other strains of $D p c$ in GenBank. The phylogenetic tree showed that the SSLP-4 isolate could be distinguished from other species of the Diaporthe/Phomopsis complex. Taken together, the results of the molecular analysis and the morphological features of the culture showed that the isolate SSLP-4 clearly belongs to $D p c$.

Pathogenicity tests were performed onto the Danbaekkong cultivar - the original plant source of the SSLP-4 isolate. For pathogenicity test on hypocotyls and detached leaves, four days later, external lesions extending from the inoculation point became visible (Fig. 4). Foliar symptoms of inoculated leaves matched a previous description showed chlorosis and necrosis edged with yellow halos surrounding each lesion (Fig. 4). No disease symptoms appeared on negative controls (Fig. 4). The pathogen was re-isolated from around the infected lesions and identified as the same species, fulfilling Koch's postulates.

For the seed bioassay, some collected seeds from plants inoculated with $P$. longicolla or $D p c$ were plated in the same petri dish to compare the morphologies of the two species. Occasionally, the $D p c$ culture produced yellowbrown pigments at the bottom of the petri dish, a phenotype markedly different from that of $P$. longicolla. In this study, isolate SSLP-4 caused a seed infection rate of 9.5\%, significantly less than the $86.6 \%$ infection rate of $P$. 


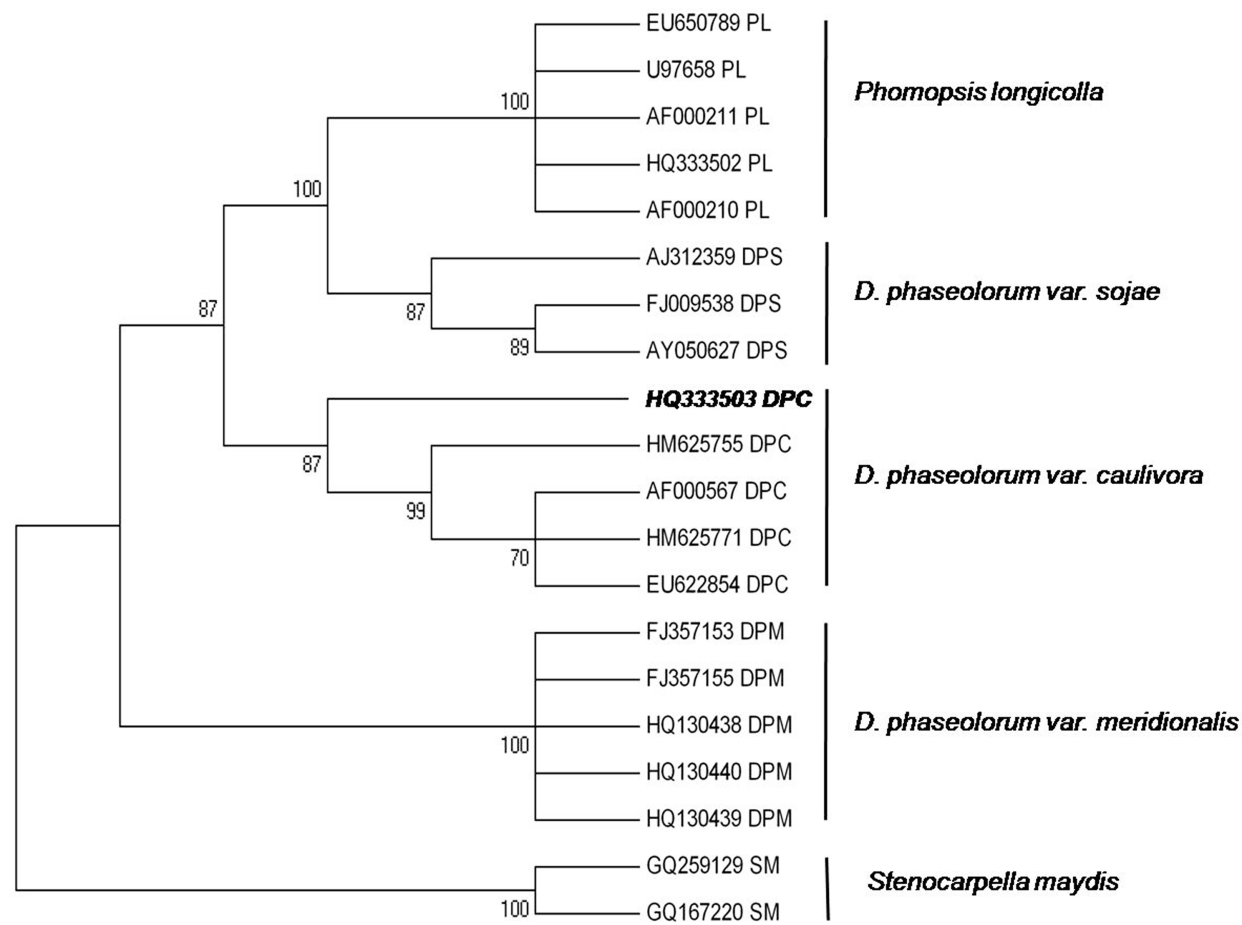

Fig. 3. Phylogenetic analysis of D. phaseolorum var. caulivora isolate SSLP-4 and related species in the Diaporthe/Phomopsis complex. The maximum-likelihood-based tree was generated from sequences of rDNA-ITS regions. The tree was rooted with Stenocarpella maydis. Our sequence is marked in bold and italic. The neighbor-joining bootstrapping values are shown below the branching nodes (>50\% out of 1,000 bootstraps).

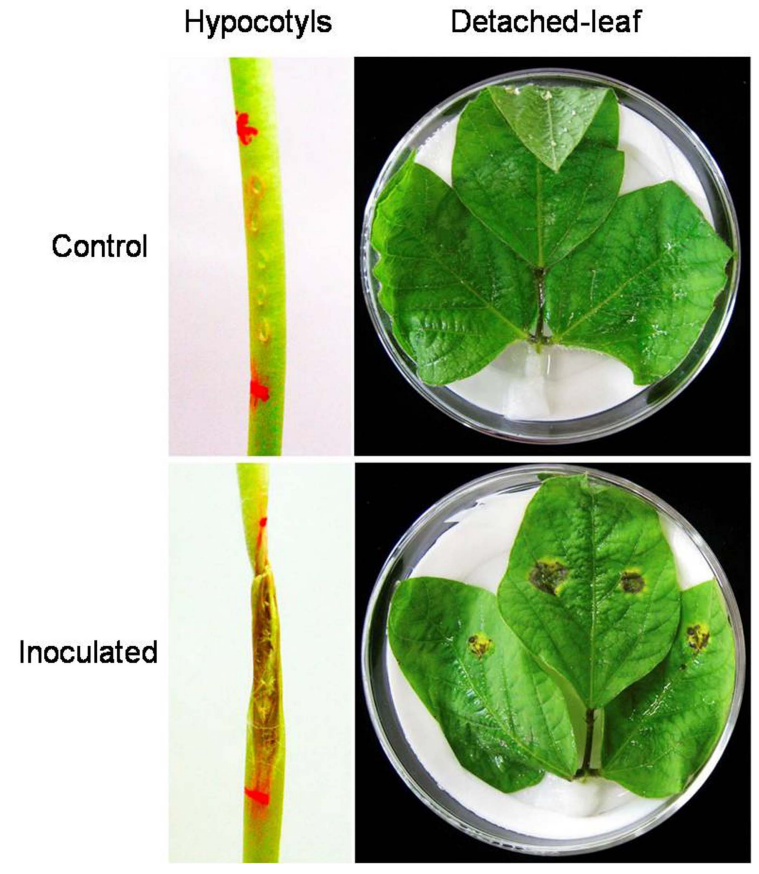

Fig. 4. Pathogenicity tests on seedling hypocotyls and adult detached-leaves. Upper panels illustrate symptom-free on control hypocotyls (inoculation points flanked by red dots) and adult leaves inoculated by sterile APDA. Lower panels show symptoms that developed on an infected hypocotyl and detached leaves inoculated by plugs of 7 day-old cultures of $D p c$ strain SSLP-4. longicolla, proving once again that $P$. longicolla is the primary causal agent of Phomopsis seed decay and that SSLP-4 is the potential pathogen causing seed decay though seed infection is not very high. Until now, only Dps and P. longicolla from the Diapothe/Phomopsis complex have been reported to cause stem blight and seed decay on soybean. However, the potential role of $D p c$ as the causative agent of seed decay has been ignored. In this study, Korean $D p c$ strain SSLP-4 was confirmed the potential of $D p c$ to contribute to seed decay, despite the single-minded emphasis on stems in previous studies. It is possible that the SSLP-4 isolate with its ability to infect stems and seeds might be a different physiological race from strains previously isolated from other geographic areas. However, any record on the physiological race of $D p c$ has not been reported though physiological races of Dpm reported in South America (Pioli et al., 2003).

Taken together, the present and previous studies on the responses of soybean germplasm to $D p c$ indicate that $D p c$ resistance may be governed in a polygenic manner depending on the developmental stage. Moreover, resistance to soybean stem canker has reported to be controlled by at least four major, dominant, nonallelic genes: $R d c 1, R d c 2$, $R d c 3$ and $R d c 4$ (Bowers et al., 1993). Thus, sources of resistance should be comprehensively screened by perform- 
ing a pathogenicity assay at multiple growth stages, including not only stems but seeds. The isolate SSLP-4 provides a Korean strain of $D p c$ that could be used as a valuable inoculum for studying soybean northern stem canker and screening resistance sources. Further quantitative trait loci mapping, following separate phenotypic analysis of stems and seeds inoculated by $D p c$, will identify genomic region(s) that confer the variations in resistance observed between stems and seeds. The identified loci will provide an answer to the question of how gene(s) for stem canker are associated with gene(s) for seed decay and whether the function of these genes is dependent or independent of plant developmental stage. These findings will help to further understand the complicated pathogenesis and defense mechanisms of Dpc.

\section{Acknowledgment}

This research was supported by a grant from the NextGeneration BioGreen 21 Program (No. PJ0080602011) of the Rural Development Administration, Republic of Korea.

\section{References}

Ash, G. J., Stodart, B., Sakuanrungsirikul, S., Anschaw, E., Crump, N., Hailstones, D. and Harper, J. D. I. 2010. Genetic characterization of a novel Phomopsis sp., a putative biocontrol agent for Carthamus lanatus. Mycologia 102:54-61.

Athow, K. L. and Caldwell, R. M. 1954. A comparative study of Diaporthe stem canker and pod and stem blight of soybean. Phytopathology 44:319-325.

Backman, P. A., Weaver, D. B. and Morganjones, G. 1985. Soybean stem canker - an emerging disease problem. Plant Dis. 69:641-647.

Bowers, G. R., Ngeleka, K. and Smith, O. D. 1993. Inheritance of stem canker resistance in soybean cultivars Crockett and Dowling. Crop Sci. 33:67-70.

Costamilan, L. M., Yorinori, J. T., Almeida, A. M. R., Seixas, C. D. S., Binneck, E., Araujo, M. R. and Carbonari, J. A. 2008.
First report of Diaporthe phaseolorum var. caulivora infecting soybean plants in Brazil. Trop. Plant Pathol. 33:381-385.

Crall, J. M. 1956. Observations on the occurrence of soybean stem canker. Phytopathology 46:10-10.

Hartman, G. L., Sinclair, J. B. and Rupe, J. C. 1999. Compendium of Soybean Diseases. 4th ed. American Phytopathological Society, St. Paul, MN, USA.

Hildebrand, A. A. 1956. Observations on stem canker and pod and stem blight of soybeans in Ontario. Can. J. Bot. 34:577599.

Keeling, B. L. 1982. A seedling test for resistance to soybean stem canker caused by Diaporthe phaseolorum var. caulivora. Phytopathology 72:807-809.

Nevena, M., Jelena, V. and Franic-Mihajlovic, D. 1997. A comparative study of Diaporthe/Phomopsis fungi on soybean from two different regions of the world. Mycopathologia 139:107113.

Pioli, R. N., Morandi, E. N., Martinez M. C., Lucca, F., Tozzini, A., Bisaro, V. and Hopp, H. E. 2003. Morphologic, molecular, and pathogenic characterization of Diaporthe phaseolorum variability in the core soybean-producing area of Argentina. Phytopathology 93:136-146.

Santos, J. M., Correia, V. G. and Phillips, A. J. L. 2010. Primers for mating-type diagnosis in Diaporthe and Phomopsis: Their use in teleomorph induction in vitro and biological species definition. Fungal Biol. 114:255-270.

Smith, E. F. and Backman, P. A. 1988. Soybean stem canker: An overview. In: Soybean Diseases of the North Central Region, eds. by T. D. Wyllie and D. H. Scott, pp. 47-55 American Phytopathological Society, St. Paul, MN, USA.

Tamura, K., Dudley, J., Nei, M. and Tamura, S. 2007. Mega4: Molecular evolutionary genetics analysis (mega) software version 4.0. Mol. Biol. Evol. 24:1596-1599.

Welch, A. W. and Gilman, J. C. 1948. Hetero-thallic and homothallic types of Diaporthe on soybeans. Phytopathology 38:628-637.

Zhang, A. W., Hartman, G. L., Riccioni, L., Chen, W. D., Ma, R. Z. and Pedersen, W. L. 1997. Using PCR to distinguish Diaporthe phaseolorum and Phomopsis longicolla from other soybean fungal pathogens and to detect them in soybean tissues. Plant Dis. 81:1143-1149. 